\title{
Ice sheet anisotropy measured with polarimetric ice sounding radar
}

Dall, Jørgen

Published in:

International Geoscience and Remote Sensing Symposium proceedings

Link to article, DOI:

10.1109/IGARSS.2010.5653528

Publication date:

2010

Document Version

Publisher's PDF, also known as Version of record

Link back to DTU Orbit

Citation (APA):

Dall, J. (2010). Ice sheet anisotropy measured with polarimetric ice sounding radar. In International Geoscience and Remote Sensing Symposium proceedings (pp. 2507-2510). IEEE.

https://doi.org/10.1109/IGARSS.2010.5653528

\section{General rights}

Copyright and moral rights for the publications made accessible in the public portal are retained by the authors and/or other copyright owners and it is a condition of accessing publications that users recognise and abide by the legal requirements associated with these rights.

- Users may download and print one copy of any publication from the public portal for the purpose of private study or research.

- You may not further distribute the material or use it for any profit-making activity or commercial gain

- You may freely distribute the URL identifying the publication in the public portal

If you believe that this document breaches copyright please contact us providing details, and we will remove access to the work immediately and investigate your claim. 


\title{
ICE SHEET ANISOTROPY MEASURED WITH POLARIMETRIC ICE SOUNDING RADAR
}

\author{
Jørgen Dall \\ National Space Institute, Technical University of Denmark \\ Ørsteds Plads 348, 2800 Kongens Lyngby, Denmark, email: jd@space.dtu.dk
}

\begin{abstract}
For polar ice sheets, valuable stress and strain information can be deduced from crystal orientation fabrics (COF) and their prevailing c-axis alignment. Polarimetric radio echo sounding is a promising technique to measure the anisotropic electromagnetic propagation and reflection properties associated with COFs. In this paper, fully polarimetric P-band data acquired with the airborne POLARIS system near the ice divide of the Greenland ice sheet are analyzed. Based on a simple electromagnetic model, these data are interpreted, and a pronounced birefringence is found.
\end{abstract}

Index Terms - Radar, sounding, P-band, polarimetry, birefringence, anisotropic reflection, ice sheets.

\section{INTRODUCTION}

The crystal orientation fabrics (COF) of polar ice sheets offer valuable stress and strain information. A prevailing caxis alignment may result from mechanical deformations [1], and in turn, COF has an impact on the flow properties of the ice. Knowledge of mechanical deformations is important when inferring past climate, explaining present ice velocities and predicting future changes of the ice sheets.

If the c-axes of the ice crystals have a prevailing alignment, the electromagnetic properties of the ice sheet become anisotropic [1], as the dielectric permittivity of a single ice crystal depends on the orientation of the polarization vector with respect to the c-axis [2]. As a result, COF formation leads to two phenomena: birefringence and reflections at abrupt COF changes. Both can be observed with a polarimetric ice sounder like the Pband Polarimetic Airborne Radar Ice Sounder (POLARIS) [3][4] developed for ESA by the Technical University of Denmark. Radar polarimetry has already proved a promising glaciological tool [5][6].

In this paper, anisotropic properties of the Greenland ice sheet are studied by analyzing polarimetric POLARIS data from a Proof-of-Concept (PoC) campaign and an Additional Test Campaign (ATC) in Greenland. First results from the PoC campaign have already been presented
[7], and in this paper these date are interpreted in terms of a simple electromagnetic model accounting for both propagation and reflection processes. Also, while the PoC data are confined to a maximum depth of about $1 \mathrm{~km}$, the ATC data cover the entire ice sheet from the surface to the bedrock. In the following, the ATC data are analyzed and interpreted as well.

\section{TEST SITES AND DATA}

The PoC campaign took place in May 2008 with the objective of testing the newly integrated system. Instrument test was also the primary motivation for the acquisition of the ATC data in October 2009, but both campaigns had a secondary objective of assessing the usefulness of polarimetric P-band data for glaciological applications.

Both the PoC data and ATC data were acquired near the ice divide as shown in Figure 1. In central Greenland, the ice sheet is stretched in the direction perpendicular to the divide, and a prevailing azimuth alignment of the c-axis is expected from theory and observed in deep ice cores [8]. Hence, the divide is well suited to the study of COF-induced anisotropic ice properties. The PoC data analyzed in this paper were acquired at $69.5^{\circ} \mathrm{N} 37.9^{\circ} \mathrm{W}$, and the ATC data were acquired at the NEEM ice core drilling site at $77.5^{\circ} \mathrm{N}$ $50.9^{\circ} \mathrm{W}$. Both campaigns comprise flight tracks perpendicular and parallel to the ice divide. The $\mathrm{H}$ and $\mathrm{V}$ polarizations are defined to be parallel and perpendicular to the flight track, respectively. Thus, at the cross-overs the $\mathrm{HH}$ polarized data from one flight track are expected to be similar to the VV data from the orthogonal flight track and vice versa.

At NEEM, where fully polarimetric ATC data were acquired, the principal axes of the anisotropy can be found by means of polarization synthesis like in [5], thereby verifying if the prevailing orientation of the c-axis of the ice crystals is indeed perpendicular to the dominating direction of the ice flow perpendicular to the ice divide. Since no cross-polarized PoC data were acquired, this is not feasible at the southern test site. 


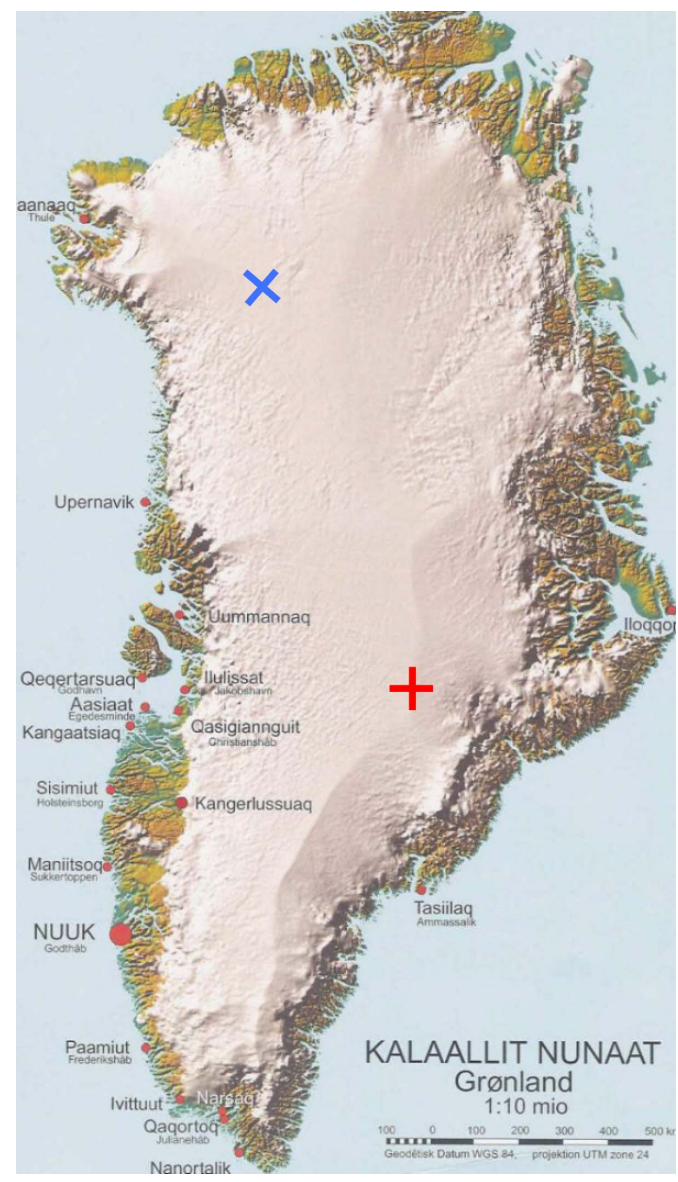

Figure 1 PoC flight tracks (red) and ATC flight tracks (blue) at ice divide.

\section{POLARIMETRIC ANALYSIS}

The POLARIS data are analyzed in terms of the complex VV-HH covariance (or coherence)

$$
c_{h h v v}\left(n_{r}, n_{a}\right)=\frac{\sum s_{h h}\left(n_{r}, n_{a}\right) s_{v v}\left(n_{r}, n_{a}\right)}{\sqrt{\sum\left|s_{h h}\left(n_{r}, n_{a}\right)\right|^{2}} \sqrt{\sum\left|s_{v v}\left(n_{r}, n_{a}\right)\right|^{2}}}
$$

here evaluated at range $n_{r}$ and azimuth $n_{a}$, and with the expectation values replaced by sums over small rangeazimuth windows. The magnitude of this coherence is a measure of the similarity of the $\mathrm{HH}$ and $\mathrm{VV}$ data. At the southern test site the HHVV coherence magnitude is almost unity down to some $200 \mathrm{~m}$, under which it drops to about 0.3 [7].

Figure 2 shows the HHVV coherence phase for a shallow sounding at the southern test site. The phase is zero at the ice surface, has large excursions between $500 \mathrm{~m}$ and $900 \mathrm{~m}$, and a more monotonous trend further down.

The same monotonous trend is seen in Figure 3a, which shows the HHVV coherence phase for a deep sounding at

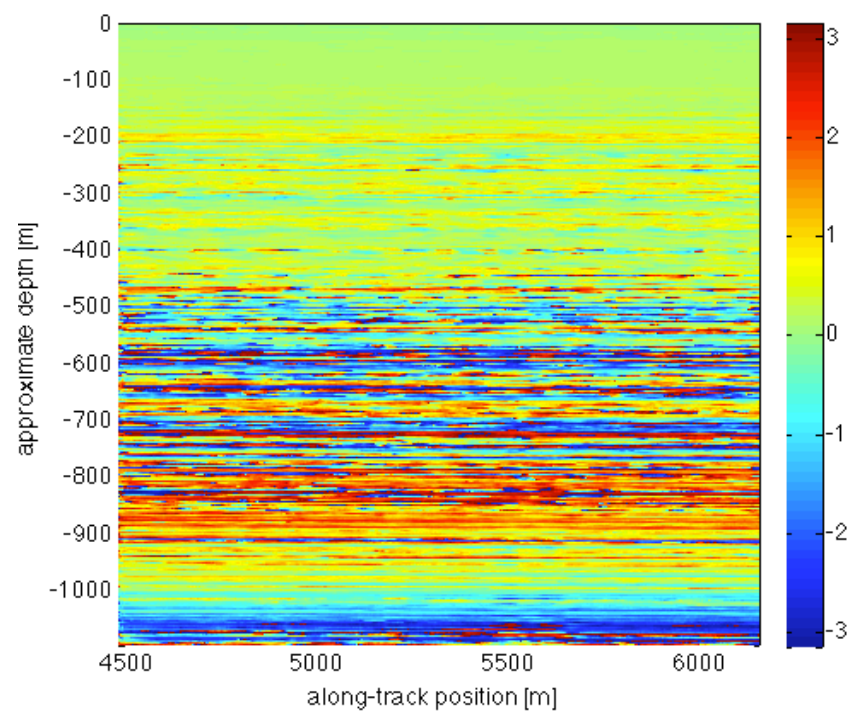

Figure $2 \mathrm{HH}-\mathrm{VV}$ phase difference in radians (PoC data, $\mathrm{H}$ parallel to the ice divide).

the NEEM site almost $1000 \mathrm{~km}$ from the first test site. The bedrock is visible at a depth of about $2560 \mathrm{~m}$. In Figure $3 \mathrm{~b}$ the phase, averaged over azimuth, is seen to increase approximately linearly, except for the modulo $2 \pi$ phase wrap. The linear trend stops at a depth of about $1500 \mathrm{~m}$. As shown in Figure 4, this is where the well-known echo-free zone starts.

\section{ELECTROMAGNETIC MODEL}

To explain the HHVV phase excursions and the monotonous phase trend further down, the complex signal received from an interface between two internal ice layers 1 and 2 at a depth of $z_{0}$ is expressed as

$$
s\left(z_{0}, \mathbf{p}\right) \propto R\left(z_{0}, \mathbf{p}\right) \cdot P\left(z_{0}, \mathbf{p}\right)
$$

where $\mathbf{p}$ is the polarization vector, $R$ a reflection factor and $P$ a propagation factor. The reflection factor in turn is the product of the Fresnel reflection coefficient $R_{1,2}$ and a geometric term $G$ (interface roughness)

$$
\begin{aligned}
& R\left(z_{0}, \mathbf{p}\right)=R_{1,2}\left(z_{0}, \mathbf{p}\right) \cdot G\left(z_{0}, \mathbf{p}\right) \\
& R_{1,2}=\frac{\sqrt{\varepsilon_{1}^{\prime}+j \varepsilon_{1}^{\prime \prime}}-\sqrt{\varepsilon_{2}^{\prime}+j \varepsilon_{2}^{\prime \prime}}}{\sqrt{\varepsilon_{1}^{\prime}+j \varepsilon_{1}^{\prime \prime}}+\sqrt{\varepsilon_{2}^{\prime}+j \varepsilon_{2}^{\prime \prime}}}
\end{aligned}
$$

The propagation factor

$$
P\left(z_{0}, \mathbf{p}\right)=\exp \left(\int_{0}^{z_{0}}-\alpha(z) d z\right) \exp \left(\int_{0}^{z_{0}}-j \frac{4 \pi f_{c}}{c(z, \mathbf{p})} d z\right)
$$




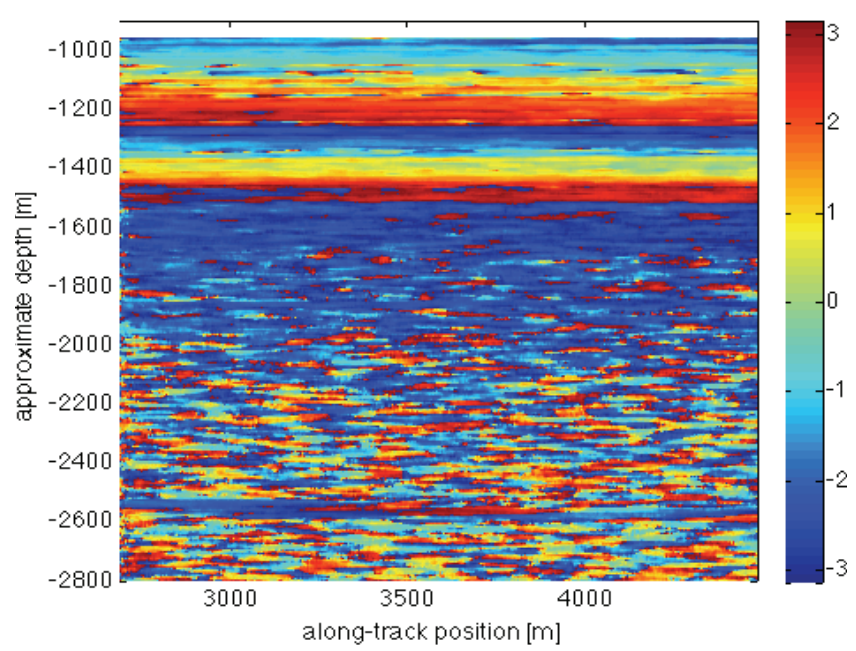

(a)

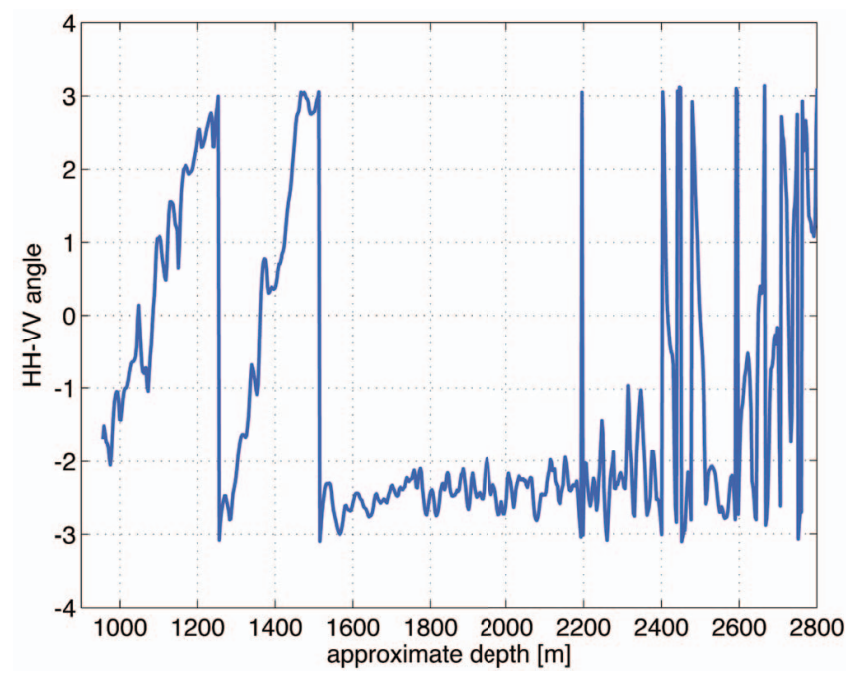

(b)

Figure $3 \mathrm{HH}-\mathrm{VV}$ phase difference in radians (ATC data, V parallel to the ice divide).

is the product of an attenuation term and a propagation phase term, which in turn is proportional to the center frequency $f_{c}$ and inversely proportional to the speed of light in ice $c$. Here, the transmit and receive polarizations are assumed to be identical. From Eq. 5 follows that the phase difference between two channels with polarizations $\mathbf{p}_{\mathrm{a}}$ and $\mathbf{p}_{b}$ has a two-way propagation phase contribution of

$$
\Delta \varphi_{a b}=-\frac{4 \pi}{\lambda_{0}} \int_{0}^{z_{0}}\left(n\left(z, \mathbf{p}_{a}\right)-n\left(z, \mathbf{p}_{b}\right)\right) d z
$$

which for an anisotropic media with a depth-independent refractive index simplifies to

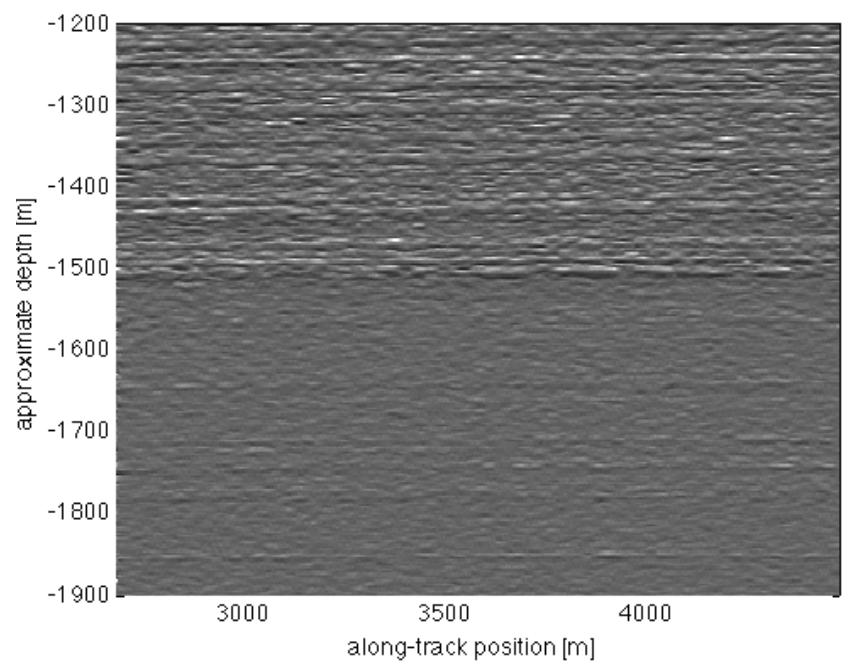

Figure 4 Internal layers in the ATC data.

$$
\Delta \varphi_{a b}=-\frac{4 \pi \Delta n}{\lambda_{0}} z_{0}
$$

where $\lambda_{0}$ is the wavelength in vacuum and $\Delta n$ is the difference between the refractive indices at the two polarizations. Eq. 7 shows that the propagation phase increases linearly with the depth of the reflecting layer $z_{0}$.

\section{DATA INTERPRETATION}

First, it has been checked that the rapid phase excursions in Figure 2 are not due to a modulo $2 \pi$ phase wrap artifact. Second, the propagation phase term cannot change rapidly as this would require an unrealistically large difference between the refractive indices at $\mathrm{HH}$ and $\mathrm{VV}$ polarizations to integrate up to a large phase change over a short depth interval, cf. Eq. 6. Therefore it is concluded that the phase excursions must be attributed anisotropic reflections (cf. Eq. 3). The fact that every resolution cell covers many internal layers means that even small (but uncorrelated) differences of the $\mathrm{HH}$ and $\mathrm{VV}$ reflections at the individual layers may result in a considerable difference of the coherently combined reflection. This mechanism is equivalent to speckle in coherent radar systems.

The monotonous phase change below $900 \mathrm{~m}$ in Figure 2 and above $1500 \mathrm{~m}$ in Figure 3 is not a system artifact, as a phase curve with the opposite slope results from data acquired from the orthogonal flight track where the $\mathrm{H}$ polarization is parallel to the divide. Instead, the phase slope is attributed birefringent propagation. The real part of the relative permittivity of anisotropic polycrystalline ice can be expressed as [9]

$$
\varepsilon^{\prime}=\varepsilon_{\perp}^{\prime}+\Delta \varepsilon^{\prime} D_{a}
$$


where $\Delta \varepsilon^{\prime}=\varepsilon_{\|}^{\prime}-\varepsilon_{\perp}^{\prime} \approx 0.037$ is the dielectric anisotropy, i.e. the difference between the permittivity for polarizations parallel and perpendicular to the c-axis of a single ice crystal. $D_{a}$ expresses the degree of alignment of the c-axes with the electrical field vector

$$
D_{a}=\frac{1}{N} \sum_{j=1}^{N} \cos \theta_{j}
$$

where the average is computed from $N$ crystals, and the caxis of the $j$ th crystal is oriented at an angle of $\theta_{j}$ with respect to the electrical field vector. $D_{a}=1$ for a fully oriented $\mathrm{COF}$ with c-axes parallel to the electrical field vector, and the variation corresponding to a randomly oriented COF is $\Delta D_{a}=1 / 3$ [9]. In Eq. $9, \theta_{j}$ depends on the polarization, so for a given COF also $D_{a}$ and hence $\varepsilon^{\prime}$ depend on the polarization. From Eq. 8 the difference between the refractive indices at $\mathrm{HH}$ and $\mathrm{VV}$ polarizations is found as

$$
\Delta n=n_{h h}-n_{v v} \approx \frac{\varepsilon_{h h}^{\prime}-\varepsilon_{v v}^{\prime}}{2 n} \approx \frac{\Delta \varepsilon^{\prime} \Delta D_{a}}{2 n} \approx 0.01 \Delta D_{a}
$$

The phase slope obtained from Figure $3 \mathrm{~b}$ is $0.021 \mathrm{rad} / \mathrm{m}$ corresponding to $\Delta D_{a}=0.12$, which is within the expected range of $1 / 3$.

Also the sign of the phase slope in Figure $3 b$ is as expected. The ice sheet is stretched in the direction perpendicular to the ice divide, and since the c-axes rotate away from the direction of stretch [8], the prevailing c-axis is in a plane parallel to the ice divide. Ice is optical positive, i.e. the ordinary polarization, perpendicular to the optical axis, has a smaller refractive index than the extraordinary polarization. In Figure $3 \mathrm{~b}$ the $\mathrm{H}$ polarization is the ordinary polarization for all crystals in the prevailing plane of crystal orientation, whereas this is not the case for the $\mathrm{V}$ polarization, which consequently is characterized by a larger refractive index. Hence, in Eq. $10 \Delta n$ is negative, and the phase difference in Eq. 7 increases with the depth, in accordance with Figure $3 b$.

\section{CONCLUSION}

The anisotropy of the Greenland ice sheet has been analyzed by means of polarimetric ice sounder data. Both the PoC data and the ATC data were acquired near the central ice divide.

No anisotropy was seen in the PoC data above a depth of some $200 \mathrm{~m}$.

Large HHVV phase excursions were found in the PoC data between 500 and $900 \mathrm{~m}$ and attributed to coherent combination of anisotropic reflections from individual layers within the resolution cells.

Further down an almost linear HHVV phase slope was found and attributed birefringent propagation. The sign of the phase slope is consistent with the expected COF orientation, and the magnitude of the phase slope suggests that the degree of orientation differs by $\Delta D_{a} \approx 0.12$ at $\mathrm{HH}$ and VV polarizations.

\section{ACKNOWLEDGEMENTS}

The POLARIS development was primarily financed by the European Space Agency (ESA). The data used in this study were acquired during Proof-of-Concept and Additional Test campaigns, which were part of the instrument development.

Anders Kusk and Steen Savstrup Kristensen, Technical University of Denmark, are acknowledged for the preprocessing of the POLARIS data.

\section{REFERENCES}

[1] O. Castelnau, H. Thorsteinsson, J. Kipfstuhl, P. Duval, and G.R. Canova, "Modeling fabric development along the GRIP ice core, Central Greenland", Annals of Glaciology, Vol. 23, pp. 194201, 1996.

[2] S. Fujita, S. Mae, T. Matsuoka, "Dielectric anisotroåy in ice Ih at 9.7 GHz", Annals of Glaciology, Vol. 17, pp. 276-280, 1993.

[3] J. Dall, S.S. Kristensen, V. Krozer, C.C. Hernández, J. Vidkjær, A. Kusk, J. Balling, N. Skou, S.S. Søbjærg, E.L. Christensen, "ESA's polarimetric airborne radar ice sounder (POLARIS): Design and first results", IET Radar, Sonar \& Navigation, Vol. 4, No. 3, pp. 488-496, 2010.

[4] J. Dall, A. Kusk, S.S. Kristensen, V. Krozer, C.C. Hernández, J. Vidkjær, J. Balling, N. Skou, S.S. Søbjærg, E.L. Christensen, "Implementation and test of POLARIS, a P-band polarimetric airborne radar ice sounder", Advanced RF Sensors for Earth Observation 2009, Noordwijk, November, 2009.

[5] S. Fujita, H. Maeno, K. Matsuoka, "Radio-wave depolarization and scattering within ice sheets: a matrix-based model to link radar and ice-core measurements and its application”, Journal of Glaciology, Vol. 52, No. 178, 2006.

[6] S. Fujita, T. Matsuoka, T. Ishida, K. Matsuoka, S. Mae, "A summary of the complex dielectric permittivity of ice in the megahertz range and its applications for radar sounding of polar ice sheets", Physics of Ice Core Records, Hokkaido University Press, 185-212, 2000.

[7] J. Dall, "Polarimetric ice sounding at P-band: First results", IEEE 2009 International Geoscience and Remote Sensing Symposium, Cape Town, July 2009.

[8] Y. Wang, T. Thorsteinsson, J. Kipfstuhl, H. Miller, D. DahlJensen, H. Shoji, "A vertical girdle fabric in the NorthGRIP deep ice core North Greenland", Annals of Glaciology, Vol. 35, pp. 515$520,2002$.

[9] S. Fujita and S. Mae, "Causes and nature of ice-sheet radioecho internal reflections estimated from the dielectric properties of ice", Annals of Glaciology, No. 20, 1994. 